\title{
Nanoporosity of MCM-41 Materials and Y-Zeolites Created by Deposition of Tournefortia hirsutissima L. Plant Extract
}

\author{
Miguel Angel Hernández, ${ }^{1}$ Gabriela Itzel Hernández, ${ }^{2}$ Roberto Portillo, ${ }^{3}$ \\ Martha Alicia Salgado, ${ }^{3}$ Fernando Rojas, ${ }^{4}$ and Vitalii Petranovskii ${ }^{5}$ \\ ${ }^{1}$ Departamento de Investigación en Zeolitas, Universidad Autónoma de Puebla, Complejo de Ciencias, Ciudad Universitaria, \\ 72570 Puebla, PUE, Mexico \\ ${ }^{2}$ Facultad de Ingeniería Química, Universidad Autónoma de Puebla, Puebla, PUE, Mexico \\ ${ }^{3}$ Facultad de Ciencias Químicas, Universidad Autónoma de Puebla, Puebla, PUE, Mexico \\ ${ }^{4}$ Departamento de Química, Universidad Autónoma Metropolitana-Iztapalapa, Apartado Postal 55-534, 09340 Mexico City, Mexico \\ ${ }^{5}$ Centro de Nanociencias y Nanotecnología, Universidad Nacional Autónoma de México, Carretera Tijuana-Ensenada, \\ Km. 107, Ensenada, BC, Mexico
}

Correspondence should be addressed to Miguel Angel Hernández; vaga1957@gmail.com

Received 13 May 2017; Revised 2 August 2017; Accepted 8 August 2017; Published 18 September 2017

Academic Editor: Bodo Fiedler

Copyright (C) 2017 Miguel Angel Hernández et al. This is an open access article distributed under the Creative Commons Attribution License, which permits unrestricted use, distribution, and reproduction in any medium, provided the original work is properly cited.

\begin{abstract}
Hybrid materials based on MCM-41 silica and Y-zeolites with a variable Si/Al ratio and an appropriate countercationic composition were prepared by impregnating inorganic substrates with an organic extract. The organic phase was previously characterized by GCMS and IRTF, while XRD, SEM, TEM, $\mathrm{N}_{2}$-physisorption, and TPD of $\mathrm{NH}_{3}$ were used to analyze the selected inorganic supports. The effect of size- and shape-selectivity was manifested in MCM-41 and Y-zeolites. Texture results confirm that the extract containing relatively large branched organic molecules is deposited in the internal voids of MCM-41 material and on the outer area of Yzeolites. In the case of Y-zeolites, the results demonstrate the effect of the $\mathrm{SiO}_{2} / \mathrm{Al}_{2} \mathrm{O}_{3}$ molar ratio and countercations on the textural properties of the samples.
\end{abstract}

\section{Introduction}

Nanomaterials such as aluminosilicate zeolites and sponge silicon dioxide are porous substances with well-defined regular pore systems. Zeolites are widely used in the industry for many applications, including catalysis, gas separation, and adsorption $[1,2]$. Mesoporous silica nanomaterials are also extensively studied for potential use in various areas [3]. Their proposed applications include medical and biological fields, which attract a great research interest $[4,5]$. These nanostructured substrates possess a high porosity and surface area, as well as a large pore volume, together with a uniform and adjustable pore size, which makes them suitable for special applications in biomedical areas $[6,7]$.

For the deposition of organic plant extracts, the loading capacity of traditional materials, such as inorganic oxides or polymer matrixes, is usually not high enough; in addition, trapped organic components cannot be selectively released without difficulties. To achieve high loading and controlled release, nanoporous materials possessing large volumes and regular structures are preferred; no doubt, these requirements are met by Y-zeolites and MCM-41 materials $[8,9]$. Their impact on living organisms and the likely toxicity were carefully considered $[10,11]$.

The loading capacity and release of active phases in the nanoporous carrier are determined by a variety of factors, including pore size, shape, connectivity, and host affinity. Microporous and mesoporous materials, such as zeolites and mesoporous silica, become important solids for the delivery of the active phase. The advantages of zeolites and mesoporous silica for biomedical applications include their biocompatibility, a large surface area, and the ability to tune 
and control their physicochemical properties. For example, Lehman and Larsen [11] mentioned the use and application of porous nanomaterials in the delivery of drugs for the treatment of various diseases. Datt et al. [12] conducted research related to intelligent nanomaterials for medicine. This review reports on the effect of nanostructured materials on the type of toxicity. Colella [13] published a review taking into account the structure, composition, and ion-exchange properties of nanoporous materials, such as clinoptilolite zeolite, for modern therapeutic applications. Pavelić et al. [14] used Ca-exchanged clinoptilolite as a potential adjuvant for the treatment of various cancers. Due to their versatility, zeolites and MCM- 41 have acquired great importance for the development of new nanomaterials. Recently, the Sanchez group reported [15] a large group of organic-inorganic hybrid nanomaterials and their applications.

The faujasite zeolite (a structure code is FAU, according to the database of the International Zeolite Association, IZA) [16] is a zeolite that has nearly spherical cavities with a diameter of $12 \AA$ connected by windows of $7.2 \AA$. This structure, as well as the inner and outer surfaces, are shown in Figure 1. Independent of their composition, all faujasites are topologically identical, but they have different properties depending on the $\mathrm{Al}$ content in their structure, giving two different materials: type X- or type Y-zeolites. The unit cell of faujasite has 192 tetrahedrally coordinated atoms, which can be $\mathrm{Al}$ or Si. Materials with the number of $\mathrm{Al}$ atoms between 96 and 77 per unit cell belong to the $\mathrm{X}$-type, and materials with a lower $\mathrm{Al}$ content belong to the Y-type. This means that the $\mathrm{SiO}_{2} / \mathrm{Al}_{2} \mathrm{O}_{3}$ molar ratio of X-zeolites is lower than 3 , and the faujasites with MR above the value of 3 appear as Y-zeolites [17].

The discovery of MCM-41 materials containing the hexagonal arrangement of one-dimensional tubular mesopores with a diameter from 20 to $100 \AA$ [17] and a large surface area has opened up new possibilities for the development of molecular sieves of this type, because their high surface areas are very attractive for the development of new adsorbents and catalysts. MCM varieties are relatively stable (thermally, hydrothermally, mechanically, and chemically) and a suitable choice of organic templates and synthesis conditions can create materials with pore diameters suitable for the adsorption of large organic molecules [18-21].

In the continuation of our earlier work [22], this paper describes the preparation and characterization of nanoporosity in hybrid materials created after the deposition of the extract of the plant Tournefortia hirsutissima L. on the outer surface of Y-zeolites and into the inner nanopores of MCM41 silica, as well as the possible use of obtained materials in the treatment of diabetic foot.

Potential advantages of this study are (i) the development of new hybrid materials by precipitation of the extract of the Tournefortia hirsutissima L. on carriers, Y-zeolites and MCM-41 silica materials; (ii) characterizing hybrid materials by various physical chemical methods; and (iii) the study of nanoporosity in these hybrid materials, which have the potential properties of cell regeneration. The experimental study on the preparation of a group of hybrid materials by means of impregnation and the influence of the preparation protocol on the secondary porosity was performed. The organic part of the hybrid materials was characterized by Gas Chromatography-Mass Spectroscopy (GC-MS), and the inorganic supports were characterized by X-Ray Diffraction (XRD), Scanning Electron Microscopy (SEM), Transmission Electron Microscopy (TEM), High-Resolution Adsorption (HRADS), Energy Dispersive Spectroscopy (EDS), and Temperature Programmed Desorption (TPD). The textural parameters such as surface area, external surface area, micropore volume, total pore volume, and pore size distribution of the microporous were calculated from the adsorption isotherms. The primary interest of this work is to obtain and analyze the morphological characteristics of nanoporous solids with highly developed surface areas, used as carriers of bioactive phases of organic nature, with the aim of getting a vehicle that allows an efficient and controlled desorption of active ingredients, constituting the organic phase deposited on the surface of such materials.

\section{Experimental Section}

2.1. Materials. MCM-41 materials were prepared in the laboratory by hydrothermal synthesis [18]. Commercial Y-zeolites with faujasite structure (FAU topology of the framework, see the WEB site of International Zeolite Association [16] for detailed description) were supplied by Zeolyst International. The faujasites with the compositions in the range of the socalled Y-zeolite, with the same topology of the structure, but with different $\mathrm{SiO}_{2} / \mathrm{Al}_{2} \mathrm{O}_{3}$ molar ratio (MR) in the range from 5.1 up to 30 and in different cationic form $\left(\mathrm{Na}^{+}, \mathrm{NH}_{4}^{+}\right.$, and $\mathrm{H}^{+}$), were selected for this work. These materials and some of their properties presented by the supplier are listed in Table 1. Labeling of samples through text and figures is listed in the last column of Table 1 and includes the type of cation, the structure of the zeolite $(\mathrm{Y})$, and the molar ratio $\mathrm{MR}$, for example, NaY5.1. For as-prepared substrates and for samples after impregnation, characters S (NaY5.1-S) or I (NaY5.1-I), respectively, are added to the label. It should be emphasized that in nominally hydrogen or ammonium forms of Y-zeolites nonetheless some amount of sodium cations is presented (see Table 1). Thermal activation of the inorganic phase substrates was done before impregnation by plant extracts (see Section 2.2.1).

\subsection{Methodology}

2.2.1. Dispersion and Stabilization of Organic Phase Nanodeposits on Y-Zeolites and MCM-41 Materials. Both Y-zeolites and MCM-41 $(5 \mathrm{~g})$ materials were dried at $373 \mathrm{~K}$ for $8 \mathrm{~h}$ and, afterward, were cooled below $300 \mathrm{~K}$ and mixed under stirring with the ethanol extract of Tournefortia hirsutissima L. $(2.5 \mathrm{~mL})$. The obtained slurry was stirred for two hours at room temperature. After this, the solvent was evaporated at $393 \mathrm{~K}$.

The initial step consists in the preparation, formation, and stabilization of nanodeposits on the surface of Y-zeolite and MCM-41 materials. These processes were carried out by impregnation and heat treatment; these steps were performed using the previously obtained liquor extract of Tournefortia hirsutissima L. in EtOH for $24 \mathrm{~h}$ under stirring. Subsequently, 


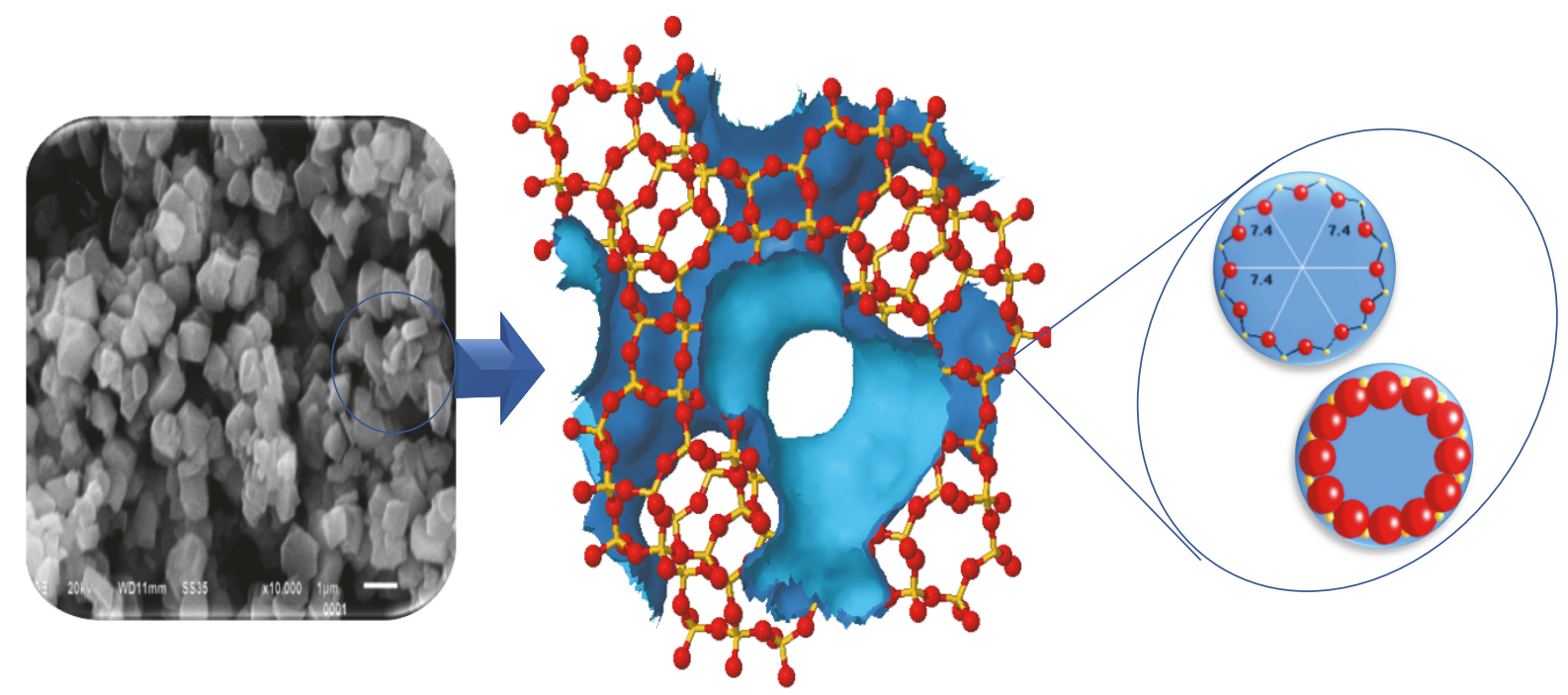

Figure 1: Surfaces in Y-zeolites.

TABLE 1: Y-zeolites supplied by Zeolyst International.

\begin{tabular}{lccccc}
\hline Zeolyst products & $\mathrm{SiO}_{2} / \mathrm{Al}_{2} \mathrm{O}_{3}$ molar ratio & Nominal cation form & $\mathrm{Na}_{2} \mathrm{O}$ weight $\%$ & Unit cell size, $\AA$ & Labeling of the samples \\
\hline CBV-100 & 5.1 & Sodium & 13.0 & 24.65 & $\mathrm{NaY5.1}$ \\
CBV-300 & 5.1 & Ammonium & 2.8 & 24.68 & $\mathrm{NH}_{4} \mathrm{Y} 5.1$ \\
CBV-400 & 5.1 & Hydrogen & 2.8 & 24.50 & $\mathrm{HY} 5.1$ \\
CBV-500 & 5.2 & Ammonium & 0.2 & 24.53 & $\mathrm{NH}_{4} \mathrm{Y} 5.2$ \\
CBV-600 & 5.2 & Hydrogen & 0.2 & 24.35 & $\mathrm{HY} .2$ \\
CBV-720 & 30 & Hydrogen & 0.03 & 24.28 & $\mathrm{HY} 30$ \\
\hline
\end{tabular}

the solvent was removed by evaporation at $363 \mathrm{~K}$. Finally, the resultant hybrid materials were stabilized at $423 \mathrm{~K}$.

2.2.2. Characterization of the Substrates and Impregnated Materials. (i) Gas chromatography-mass spectrometry (GC$M S$ ) analysis of the extract was performed by means of a coupled system of an Agilent Model 7890A gas chromatograph and an Agilent Model 5975 mass spectrometer and has been previously reported [23].

(ii) $X$-ray diffraction $(X D R)$ test samples were performed with a Siemens $\mathrm{D} 500$ diffractometer using a $\mathrm{Cu} \mathrm{K}_{\alpha}$ radiation ( $\lambda=1.54 \AA$ ), operating at $40 \mathrm{kV}$ and $30 \mathrm{~mA}$. The samples were previously ground. Crystalline phases were identified with the help of cards supplied by the Joint Committee on Powder Diffraction Standards (JCPDS) and Collection of XRD Patterns for zeolites edited by IZA [24]. Samples were analyzed over a diffraction angle range $2 \theta=1-6^{\circ}$ for MCM41 materials and $2 \theta=5-65^{\circ}$ for Y-zeolites, employing a step size of $0.03^{\circ}$ and a time of $6 \mathrm{~s}$.

(iii) Scanning Electron Microscopy (SEM) was performed using a JEOL JSM-5300 electron microscope (SEM) employing a tungsten filament operated at $10 \mathrm{kV}$ at $298 \mathrm{~K}$. Photomicrographs of the surface were gotten and the morphology of obtained materials was observed and chemical analyses were performed through energy dispersive spectroscopy (EDS). (iv) Transmission Electron Microscopy (TEM) was performed on TITAN 80 operated at $300 \mathrm{kV}$.

(v) Fourier Transform Infrared Spectroscopy (FTIR) analyses were carried out in a Bruker Vector spectrometer.

(vi) $\mathrm{N}_{2}$ adsorption isotherms were determined at the boiling temperature of liquid nitrogen $(77 \mathrm{~K}$ at the 2,150 $\mathrm{m}$ altitude of Puebla, Mexico) applying fully automated volumetric instrument (Autosorb1LC, Quantachrome Corp.). This system was previously calibrated with reference adsorbents. Adsorption isotherms were determined in the range of relative pressure, $p / p^{0}$ from $10^{-6}$ to $1 ; p^{0}$ is the saturation $\mathrm{N}_{2}$ pressure and it was continuously recorded throughout the experiment. Prior to the $\mathrm{N}_{2}$ sorption runs, each sample was degassed at $200^{\circ} \mathrm{C}$ for $20 \mathrm{~h}$ under a vacuum of $10^{-6} \mathrm{mbar}$. Textural parameters (surface areas and pore volumes) were obtained from the analysis of sorption isotherms by means of (i) the BET [25] equation, (ii) the Langmuir equation [26], (iii) the method of external area [27], and (iv) the Gurvitsch rule [28]. The pore size distribution of the samples under study was obtained from the data, processing the boundary desorption curves through the BJH method [29].

(vii) Temperature Programmed Desorption (TPD) of $\mathrm{NH}_{3}$ was used to characterize acid sites on the substrates. This process was carried out by chemisorption of a $\mathrm{NH}_{3} / \mathrm{He}$ gas mixture at different adsorption temperatures. The instrument 


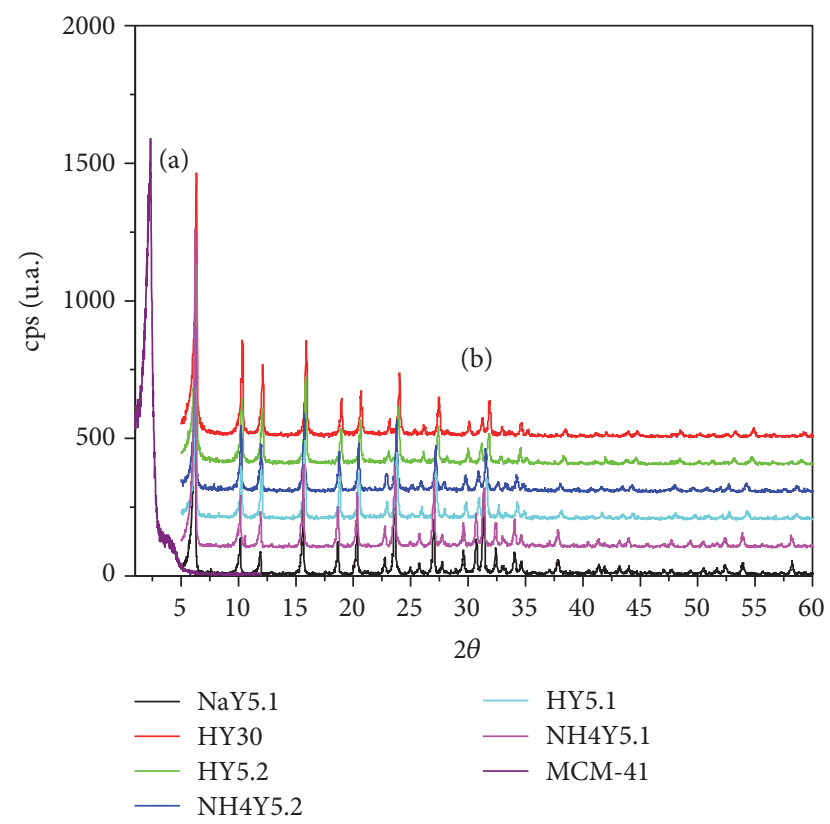

FIGURE 2: XRD patterns of (a) MCM-41 and (b) Y-zeolites.

used was an Autosorb-1C-MS Quantachrome automatic sorption characterization device.

\section{Results and Discussion}

3.1. GS-MS. The chemical composition and the mass percentage of each of the components presented in the active phase of the Tournefortia hirsutissima L. ethanol extract were estimated by GC-MS and have been previously reported [23]. Table 2 summarizes the information of the compounds detected by gas chromatography that exist in higher concentrations, together with their retention times and identification factor for each one of them. This table shows that 1,2-benzenedicarboxylic acid, mono (2-ethylhexyl) ester (21.04\%), $\gamma$-sitosterol (16.42\%), and 3,7,11,15-tetramethyl-2hexadecen-1-ol (6.34\%) are the three main components, followed by hexadecanoic acid, ethyl ester (4.77\%), phenol, $2,2^{\prime}$-methylene bis (4.53\%), (E)-9-octadecenoic acid ethyl ester $(4.11 \%)$, and hexadecanoic acid, methyl ester (4.08\%).

3.2. X-Ray Diffraction. Diffraction patterns of the materials under study at $2 \theta=2-6^{\circ}$ for the MCM-41 materials and at $2 \theta=5-65^{\circ}$ for the Y-zeolites are shown in Figure 2. In the diffraction pattern of MCM-41 materials predominant signals were observed at approximately $2 \theta=2^{\circ}$; however, these signals are relatively wide thus manifesting an amorphous character. It appears that higher $2 \theta$ values than the usual ones indicate some contraction of the structure of this material. The diffraction patterns of Y-zeolites (JCPDS card 33-1270.) exhibit typical signals of such materials. The predominant peaks appear at $2 \theta: 6.19^{\circ}, 15.61^{\circ}, 18.64^{\circ}, 20.3^{\circ}, 23.6^{\circ}, 26.97^{\circ}$, $31.32^{\circ}$, and $33.99^{\circ}$.

3.3. Scanning Electron Microscopy. The analysis performed on the same sample by using Scanning Electron Microscopy shows Y-zeolite aggregates, as well as thin crystals of cubic form and varying sizes of about $1 \mu \mathrm{m}$ (Figures $3(\mathrm{a})$ and $3(\mathrm{~b})$ ).

3.4. Transmission Electron Microscopy. TEM analysis was performed for the MCM-41-S specimen; the corresponding micrograph unveiled the presence of well-defined and ordered channels (Figures 3(c)-3(d)).

3.5. Energy Dispersive Spectroscopy. Studies of Y-zeolites indicate that MR ratio remains constant after impregnation; with respect to the abundance of $\mathrm{Na}_{2} \mathrm{O}$, the following sequence is set up: NaY5.1 > $\mathrm{NH}_{4} \mathrm{Y} 5.1=\mathrm{HY} 5.1>\mathrm{NH}_{4} \mathrm{Y} 5.2=\mathrm{HY} 5.2$ $>\mathrm{HY} 30$, which coincide with the sequence of the provider values (Table 1). It means that ion content is not changed during the treatment. Meanwhile, the size of the unit cell is similar for all Y-zeolites, Table 1.

3.6. FTIR. The infrared spectra of the Tournefortia Ethanolic Extract (TEE) in solution and with impregnated Y-zeolites and MCM-41 nanomaterials have the following features. The most intense absorptions were observed in the range of (a) $400-1700 \mathrm{~cm}^{-1}$ and (b) $2800-3800 \mathrm{~cm}^{-1}$, Figures 4 (a) and 4 (b). The infrared spectrum has the following features $\left(\mathrm{cm}^{-1}\right)$ : 3300 typical absorption of C-H stretch in alcohols and phenols; 2900 absorption characteristic of $\mathrm{C}-\mathrm{H}$ stretch of methylene groups; 1720 typical of $\mathrm{C}=\mathrm{O}$ stretching vibrations of carbonyl group; $1450 \mathrm{~cm}^{-1}$ of $\mathrm{CH}_{2}$; and 1400 typical of $\mathrm{COCH}_{3}$; other absorption peaks include $1200 \mathrm{~cm}^{-1}(\mathrm{OH})$, $1100 \mathrm{~cm}^{-1}$ (cycloalkane), and $950 \mathrm{~cm}^{-1}$ [23]. The framework vibration bands of Y-zeolite show the spectra below $1200 \mathrm{~cm}^{-1}$ in the regions 750 and $700 \mathrm{~cm}^{-1}$, which are attributed to double ring, symmetric stretching, and asymmetric stretching vibrations, respectively [30].

3.7. Analysis of the Adsorption Isotherms. The $\mathrm{N}_{2}$ sorption isotherms at $77 \mathrm{~K}$, that is, relative pressure, $p / p^{0}$ versus adsorbed volume in $\mathrm{cm}^{3}$ STP per gram of material are shown in Figure 5.

These isotherms correspond to the samples before and after being impregnated with the alcoholic extract of Tournefortia hirsutissima L. plant. These sorption isotherms are of Type IV in the IUPAC classification for the MCM-41 substrates. In turn, the $\mathrm{N}_{2}$ sorption isotherms of the Y-zeolites are Type Ia in the same classification [31]. The results of the textural studies of the samples, before (S) and after impregnation (I), are reported in Table 3 . It can be observed that a greater adsorption capacity of the MCM-41-S material exists, along with the entire $p / p^{0}$ range if compared to the case of Yzeolites. However, when this material has been impregnated with the extract solution, the adsorption capacity for the MCM-41-I material is considerably diminished, since the extract is deposited in the interior of the structure voids, thus blocking the pore cavities of this material. There is a decrease in the available volume by approximately 3.5 times. This behavior may be related to the effect of size selectivity depicted by MCM-41 materials. The textural properties of the samples, before (S) and after impregnation (I), conform to the following order according to their adsorption values. 


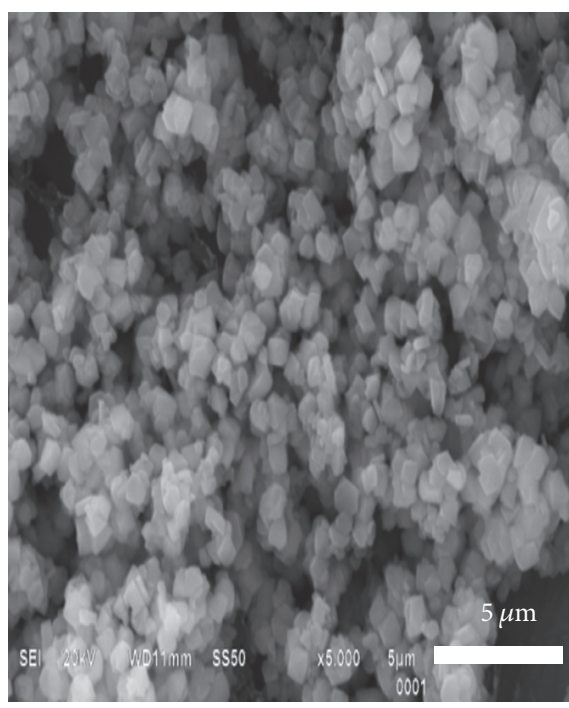

(a)

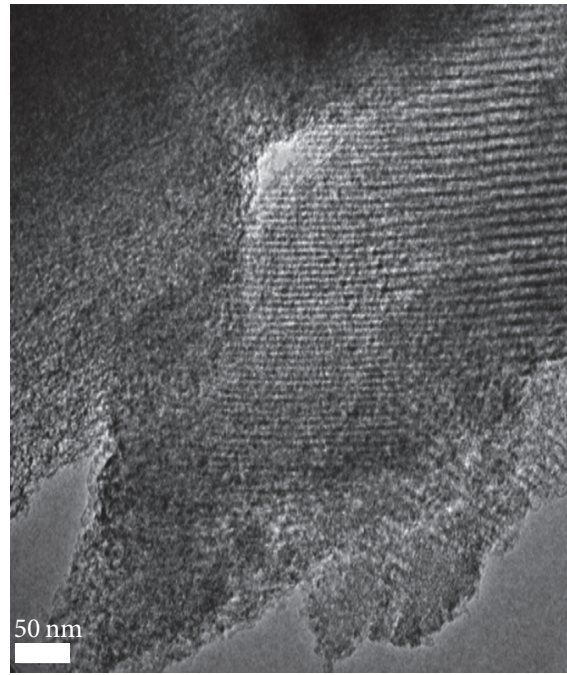

(c)

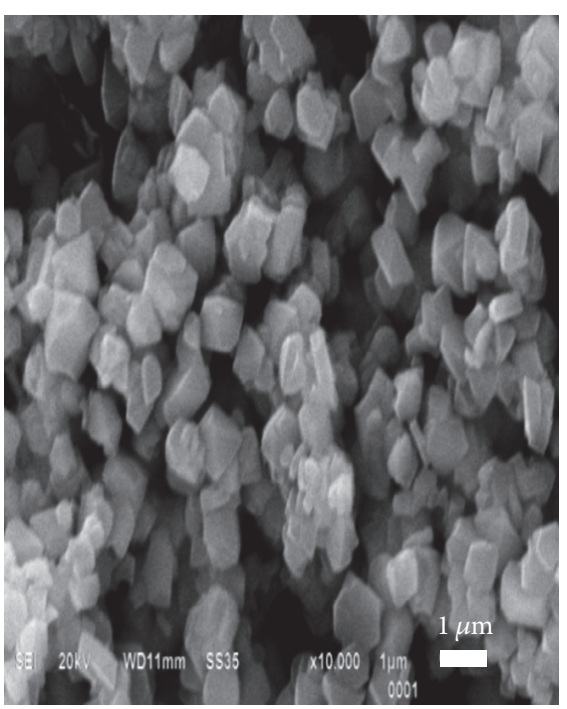

(b)

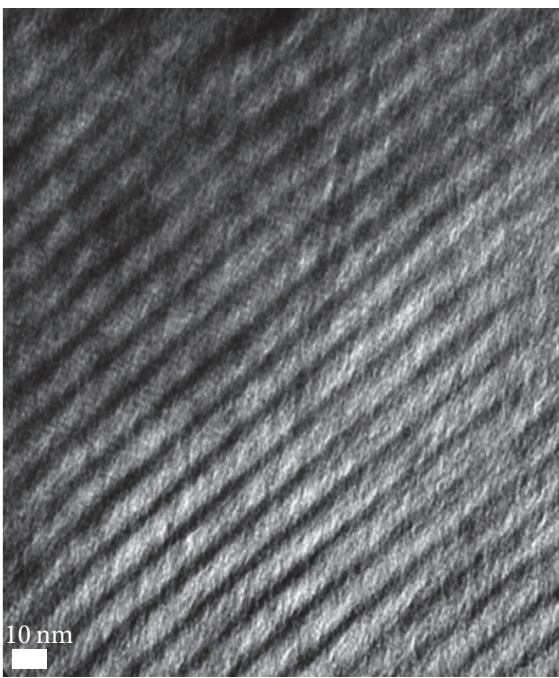

(d)

Figure 3: SEM images of Y-zeolites (a-b) and TEM images of MCM-41 materials synthetic samples with different crystal sizes (c-d).

TABle 2: Principal organic molecule composition of the ethanolic extract of Tournefortia hirsutissima L. as measured by GC-MS.

\begin{tabular}{|c|c|c|c|c|}
\hline $\begin{array}{l}\text { RT } \\
\text { min }\end{array}$ & Compound & Formula & $\begin{array}{c}M \\
\mathrm{~g} \mathrm{~mol}^{-1}\end{array}$ & $\begin{array}{c}\mathrm{RC} \\
\%\end{array}$ \\
\hline 11.878 & 3,7,11,15-Tetramethyl-2-hexadecen-1-ol (Phytol) & $\mathrm{C}_{20} \mathrm{H}_{40} \mathrm{O}$ & 296 & 6.34 \\
\hline 12.732 & Hexadecanoic acid, methyl ester & $\mathrm{C}_{25} \mathrm{H}_{42} \mathrm{O}_{2}$ & 374 & 4.08 \\
\hline 13.334 & Phenol, 2,2'-methylene bis & $\mathrm{C}_{13} \mathrm{H}_{12} \mathrm{O}_{2}$ & 200 & 4.53 \\
\hline 13.389 & Hexadecanoic acid, ethyl ester & $\mathrm{C}_{18} \mathrm{H}_{36} \mathrm{O}_{2}$ & 284 & 4.77 \\
\hline 14.998 & (E)-9-Octadecenoic acid ethyl ester & $\mathrm{C}_{20} \mathrm{H}_{38} \mathrm{O}_{2}$ & 310 & 4.11 \\
\hline 19.804 & 1,2-Benzenedicarboxylic acid, mono(2-ethylhexyl) ester & $\mathrm{C}_{16} \mathrm{H}_{22} \mathrm{O}_{4}$ & 278 & 21.04 \\
\hline 55.946 & $\gamma$-Sitosterol & $\mathrm{C}_{29} \mathrm{H}_{50} \mathrm{O}$ & 414 & 16.42 \\
\hline
\end{tabular}

RT: retention time, M: molecular mass, and RC: relative concentration (\%) of Tournefortia hirsutissima L. of ethanolic extract. 
TABLE 3: Textural parameters of FAU-CBV zeolites and MCM-41 materials determined from $\mathrm{N}_{2}$ adsorption before (S) and after being impregnated (I) with Tournefortia ethanolic extract.

\begin{tabular}{|c|c|c|c|c|c|c|c|c|}
\hline Materials & $\begin{array}{c}A_{\mathrm{SB}} \\
\mathrm{m}^{2} \mathrm{~g}^{-1}\end{array}$ & $C_{B}$ & $\begin{array}{c}A_{\mathrm{SL}} \\
\mathrm{m}^{2} \mathrm{~g}^{-1}\end{array}$ & $\begin{array}{c}A_{\mathrm{St}} \\
\mathrm{m}^{2} \mathrm{~g}^{-1}\end{array}$ & $\begin{array}{c}V_{\Sigma} \\
\mathrm{cm}^{3} \mathrm{~g}^{-1}\end{array}$ & $\begin{array}{c}W_{0 t} \\
\mathrm{~cm}^{3} \mathrm{~g}^{-1}\end{array}$ & $\begin{array}{c}V_{\text {meso }} \\
\mathrm{cm}^{3} \mathrm{~g}^{-1}\end{array}$ & $\begin{array}{c}\text { Pore diameter } \\
\text { BJH, } \AA\end{array}$ \\
\hline \multicolumn{9}{|l|}{ Before } \\
\hline CBV-100-S & 670 & -37 & 1018 & 38 & 0.395 & 0.335 & 0.06 & 51,106 \\
\hline CBV-300-S & 601 & -55 & 882 & 31 & 0.326 & 0.291 & 0.035 & \\
\hline CBV-400-S & 604 & -61 & 886 & 84 & 0.275 & 0.265 & 0.010 & \\
\hline CBV-500-S & 678 & -61 & 994 & 127 & 0.414 & 0.284 & 0.130 & 72 \\
\hline CBV-600-S & 529 & -65 & 772 & 101 & 0.378 & 0.217 & 0.161 & \\
\hline CBV-720-S & 725 & -80 & 1060 & 121 & 0.496 & 0.306 & 0.190 & 34 \\
\hline MCM-41-S & 1009 & 52 & 1185 & 1009 & 0.777 & 0 & 0.777 & 24,34 \\
\hline \multicolumn{9}{|l|}{ Impregnated } \\
\hline CBV-100-I & 692 & -53 & 1016 & 38 & 0.369 & 0.335 & 0.034 & \\
\hline CBV-300-I & 462 & -56 & 680 & 44 & 0.267 & 0.214 & 0.053 & \\
\hline CBV-400-I & 604 & -61 & 886 & 84 & 0.363 & 0.265 & 0.098 & 36,103 \\
\hline CBV-500-I & 678 & -61 & 994 & 96 & 0.414 & 0.297 & 0.117 & \\
\hline CBV-600-I & 526 & -65 & 772 & 101 & 0.378 & 0.217 & 0.161 & $36,47,151$ \\
\hline CBV-720-I & 725 & -80 & 1060 & 124 & 0.496 & 0.304 & 0.192 & 36 \\
\hline MCM-41-I & 286 & 78 & 415 & 286 & 0.309 & 0 & 0.309 & 36 \\
\hline
\end{tabular}

$A_{\mathrm{sB}}$ is the specific surface area BET; $A_{\mathrm{sL}}$ is the specific surface area Langmuir; $A_{\mathrm{st}}$ is the external surface area $t$-method; $C_{B}$ is the BET constant; $V_{\Sigma}$ is the volume adsorbed close to saturation $\left(p / p^{0}=0.95\right)$, calculated as volume of liquid (Gursvitch rule); $W_{0 t}$ is micropore volume calculated by $t$-plots; $V_{\text {meso }}$ is mesopore volume; and Pore diameter $\mathrm{BJH}$ is the pore size estimated by BJH method.

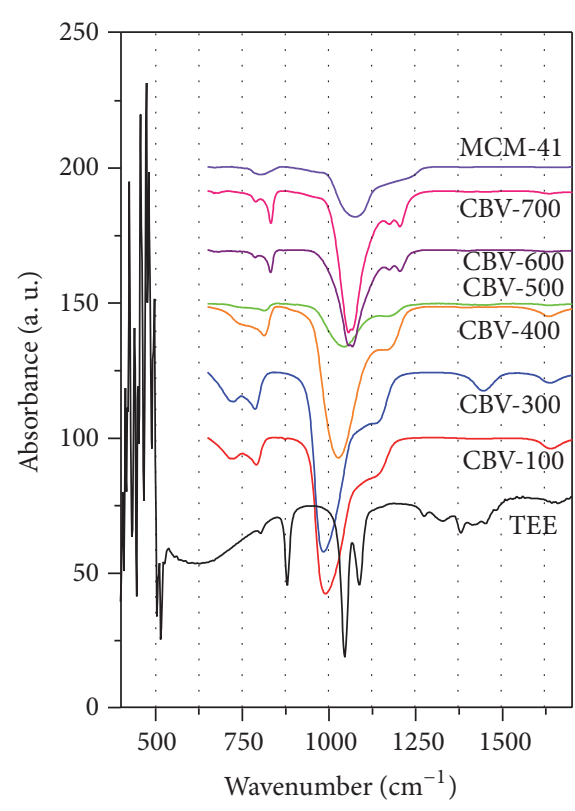

(a)

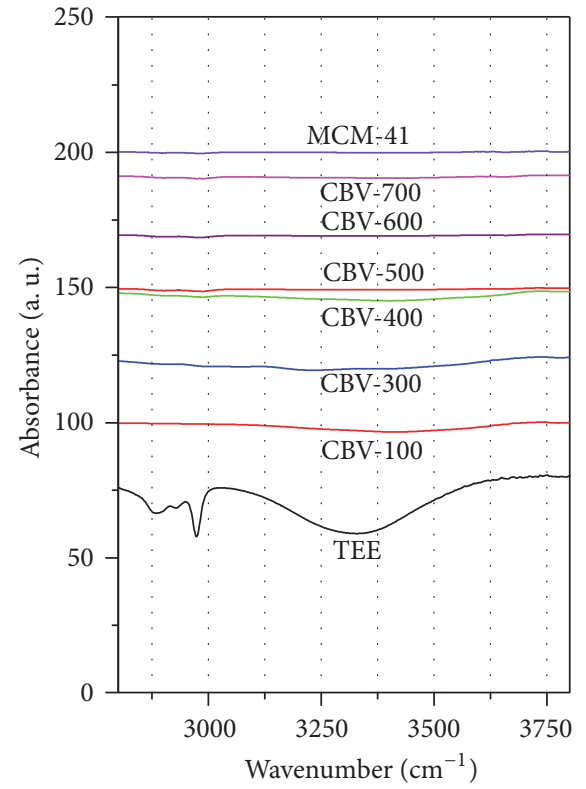

(b)

FIgURE 4: FTIR spectra of Tournefortia Ethanolic Extract (TEE) in solution and with impregnated materials, (a) $400-1700 \mathrm{~cm}^{-1}$ and (b) $2800-3800 \mathrm{~cm}^{-1}$. 


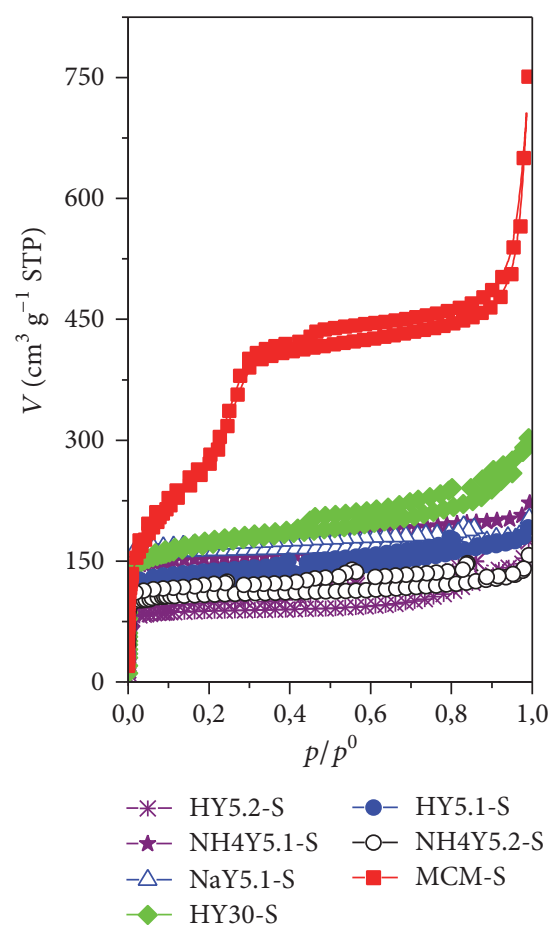

(a)

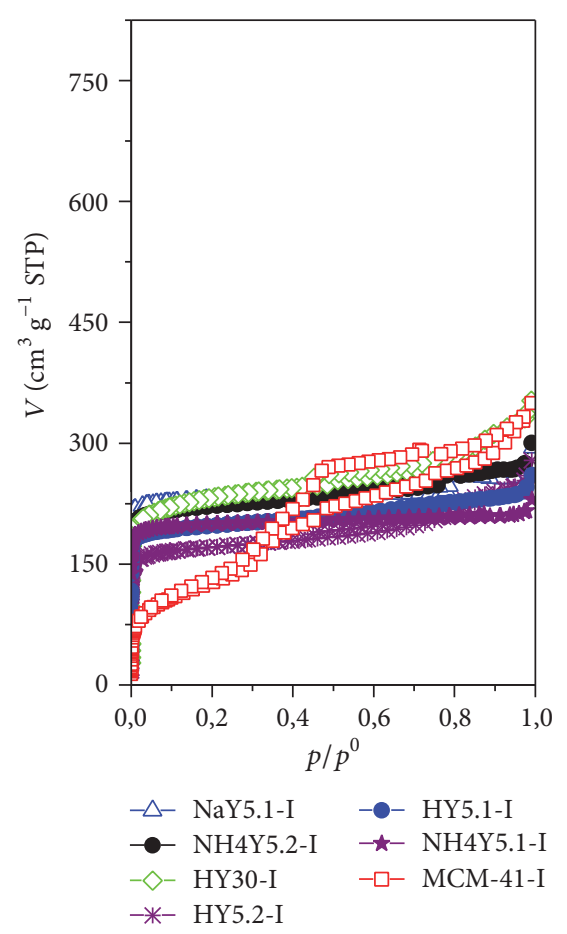

(b)

FIGURE 5: $\mathrm{N}_{2}$ adsorption isotherms at $77 \mathrm{~K}$ on Y-zeolites and MCM-41 materials: (a) nonimpregnated and (b) impregnated with ethanolic solution.

Initial Substrates before Impregnation

$$
\begin{aligned}
& A_{\mathrm{SB}}\left(\mathrm{m}^{2} \mathrm{~g}^{-1}\right): \text { HY30-S }>\mathrm{NH}_{4} \mathrm{Y} 5.2-\mathrm{S}>\mathrm{NaY} 5.1-\mathrm{S}> \\
& \text { HY5.1-S }>\mathrm{NH}_{4} \mathrm{Y} 5.1-\mathrm{S}>\mathrm{HY} 5.2-\mathrm{S} \\
& V_{\Sigma}\left(\mathrm{cm}^{3} \mathrm{~g}^{-1}\right): \text { HY30-S }>\mathrm{NH}_{4} \mathrm{Y} 5.2-\mathrm{S}>\mathrm{NaY} 5.1-\mathrm{S}> \\
& \mathrm{HY} 5.2-\mathrm{S}>\mathrm{NH}_{4} \mathrm{Y} 5.1-\mathrm{S}>\mathrm{HY} 5.1-\mathrm{S} \\
& W_{0 t}:\left(\mathrm{cm}^{3} \mathrm{~g}^{-1}\right): \mathrm{NaY} 5.1-\mathrm{S}>\mathrm{HY} 30-\mathrm{S}>\mathrm{NH}_{4} \mathrm{Y} 5.1-\mathrm{S}> \\
& \mathrm{NH}_{4} \mathrm{Y} 5.2-\mathrm{S}>\mathrm{HY} 5.1-\mathrm{S}>\mathrm{HY} 5.2-\mathrm{S}
\end{aligned}
$$

\section{Impregnated Materials}

$$
\begin{aligned}
& A_{\mathrm{SB}}\left(\mathrm{m}^{2} \mathrm{~g}^{-1}\right): \text { HY30-I }>\mathrm{NaY} 5.1-\mathrm{I}>\mathrm{NH}_{4} \mathrm{Y} 5.2-\mathrm{I}> \\
& \text { HY5.1-I > HY5.2-I > NH } 4 \text { Y5.1-I } \\
& V_{\Sigma}\left(\mathrm{cm}^{3} \mathrm{~g}^{-1}\right): \text { HY30-I }>\mathrm{NH}_{4} \mathrm{Y} 5.2-\mathrm{I}>\mathrm{HY} 5.2-\mathrm{I}> \\
& \text { NaY5.1-I > HY5.1-I > NH } 4 \text { Y5.1-I } \\
& W_{0 t}\left(\mathrm{~cm}^{3} \mathrm{~g}^{-1}\right): \text { NaY5.1-I }>\text { HY30-I }>\mathrm{NH}_{4} \mathrm{Y} 5.2-\mathrm{I}> \\
& \text { HY5.1-I > HY5.2-I > } \mathrm{NH}_{4} \text { Y5.1-I }
\end{aligned}
$$

Regarding the Y-zeolites, the deposition of the extract is performed on the outer surface area of these materials, and their textural properties do not change noticeably after the impregnation.

3.8. Pore Size Distribution. The pore size distribution (PSD) functions for impregnated samples were obtained by the method of Barrett-Joyner-Halenda, BJH, by using the desorption points of the respective isotherms (Figures 6(a) and $6(\mathrm{~b})$ ). It can be seen in Figure 6(a) that PSD curves of Yzeolites before impregnation produce unimodal distributions with peaks occurring at specific values of pore diameters for zeolite HY30-S (74 $\AA$ ) and bimodal (51 and $106 \AA$ ) for zeolite NaY5.1-S. It can be noted the MCM-41-S materials possess bimodal distributions arising at 24 and $34 \AA$. Meanwhile, the PSD distribution curves of the impregnated materials render unimodal distributions for the MCM-41-I specimen centered at $36 \AA$. The HY5.2-I zeolite sample shows bimodal distributions centered at 26 and $47 \AA$, Figure 6(b). The results of these PSD estimations are listed in the last column of Table 2.

3.9. Temperature Programmed Desorption (TPD). $\mathrm{NH}_{3} \mathrm{TPD}$ curves associated with the acidity of protonic zeolites, such as HY5.1, HY5.2, and HY30 herein studied, usually, demonstrate peaks in two temperature ranges (see Figure 7). These intervals lie within 150 to $300 \mathrm{~K}$ and 350 to $600 \mathrm{~K}$ and are referred to as low temperature (LT) and high temperature (HT) intervals, respectively. The peaks in the LT region are attributed to the desorption of weakly bound $\mathrm{NH}_{3}$. The peaks in the $\mathrm{HT}$ range can be attributed to ammonia desorption from Brønsted acid sites and strong Lewis ones. The maximum temperature desorption peak was used to characterize the strength of acidity according to the classification. The NaY5.1, $\mathrm{NH}_{4} \mathrm{Y} 5.1, \mathrm{NH}_{4} \mathrm{Y} 5.2, \mathrm{HY} 5.2$, and HY30 samples showed $\mathrm{NH}_{3}$ TPD profiles consistent with those reported in the literature [32]. The $\mathrm{NH}_{4} \mathrm{Y} 5.1$ zeolite has the highest total acidity in the two defined regions. The position of the high-temperatures desorption peak of $\mathrm{NH}_{3}$ (around $660^{\circ} \mathrm{C}$ ) is the same as the position of dehydroxylation peak. The dehydroxylation and deammoniation occur from the strongest acid sites. The population of these strongest Brønsted sites determined after 


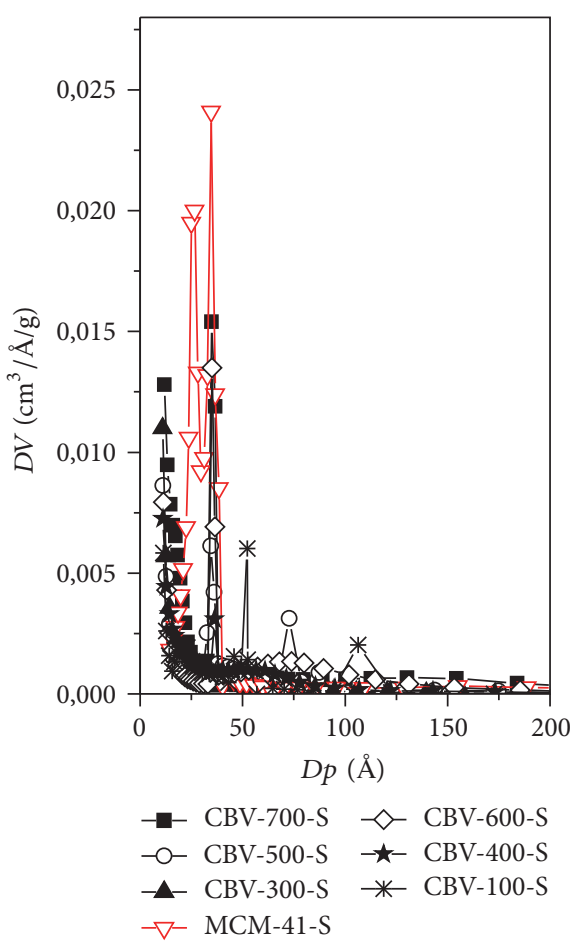

(a)

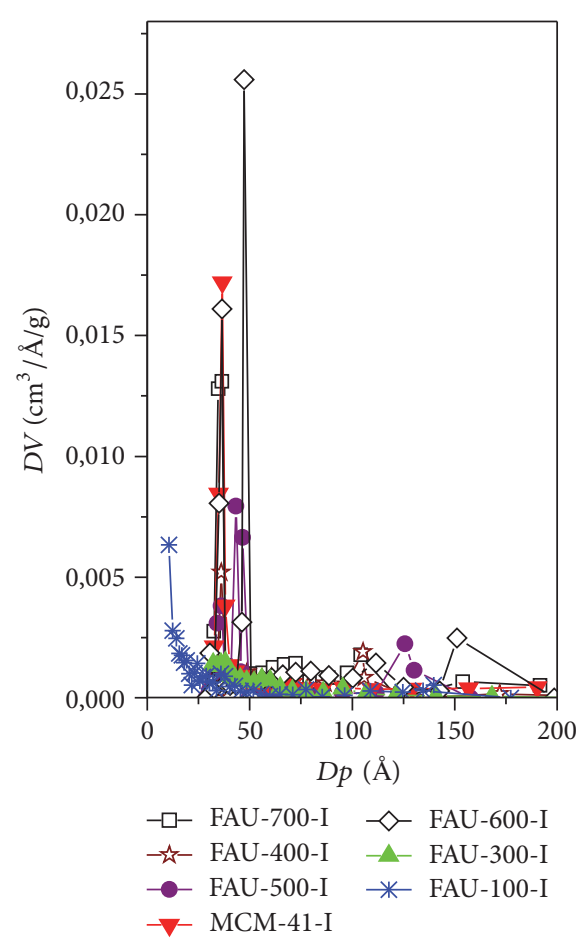

(b)

FIGURE 6: PSDs of Y-zeolites and MCM-41 materials calculated from the BJH method: (a) nonimpregnated and (b) impregnated.

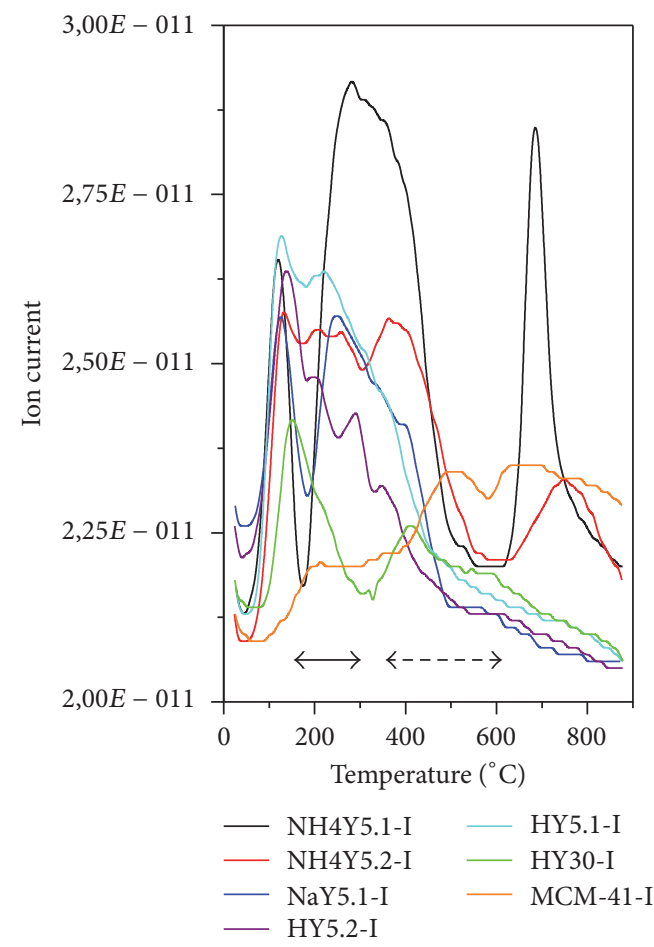

(a)

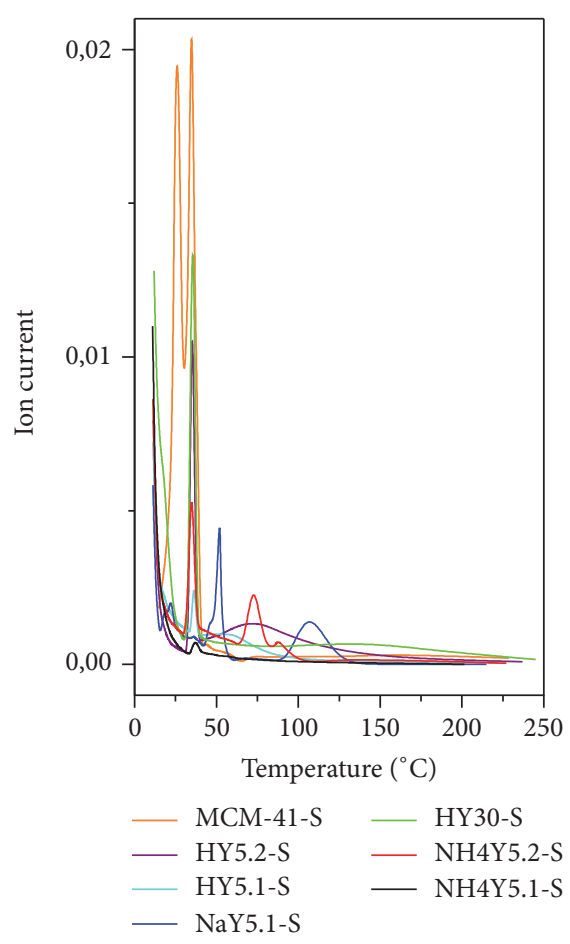

(b)

FIGURE 7: TPD of $\mathrm{NH}_{3}$ in Y-zeolites and MCM-41 materials: (a) impregnated and (b) nonimpregnated. 
deconvolution of the TPD spectra is a small fraction of the total number of sites.

\section{Conclusions}

A group of microporous and mesoporous hybrid materials was obtained; these inorganic substrates were impregnated with a bioactive organic phase. The active phase could be introduced and stabilized inside the internal surface of the voids of MCM-41 materials. Meanwhile, the same extract was deposited on the outer surface of the Y-zeolites. The chemical composition of the ethanol Tournefortia hirsutissima L. extract indicates that a group of compounds exists constituting the mixture, in which 1,2-benzenedicarboxylic acid, mono(2-ethylhexyl) ester, and $\gamma$-sitosterol prevail as the most abundant compounds. XRD analysis was performed at low and normal angles. $\mathrm{N}_{2}$ adsorption indicates the adsorption capacity is clearly affected after extract impregnation has been performed in the supporting materials; this appears so since the surface area is covered with the bioactive organic phase and results in a decreasing surface area. The pore size distribution indicates a bimodal pore character for the NaY5.1-S zeolites material while in the case of MCM-41-S the behavior is similar to these materials. On the other hand, HY5.1-I has a bimodal character and renders a multimodal character HY5.2-I, so projecting the HY5.2-I acidity and study shows that there are different acid sites (strengths and weaknesses).

\section{Conflicts of Interest}

The authors declare that they have no conflicts of interest.

\section{References}

[1] M. Sun, C. Chen, L. Chen, and B. Su, "Hierarchically porous materials: Synthesis strategies and emerging applications," Frontiers of Chemical Science and Engineering, vol. 10, no. 3, pp. 301347, 2016.

[2] S. F. Anis, A. Khalil, Saepurahman, G. Singaravel, and R. Hashaikeh, "A review on the fabrication of zeolite and mesoporous inorganic nanofibers formation for catalytic applications," Microporous and Mesoporous Materials, vol. 236, pp. 176192, 2016.

[3] B. Subotić, T. Antonić, and J. J. Bronić, "Theoretical basis of the gel "memory effect" and its implications on the controlling of the particulate properties of zeolites," in From Zeolites to Porous MOF Materials - The 40th Anniversary of International Zeolite Conference, Proceedings of the 15th International Zeolite Conference, vol. 170 of Studies in Surface Science and Catalysis, pp. 233-241, Elsevier, 2007.

[4] W. J. Parak, D. Gerion, T. Pellegrino et al., "Biological applications of colloidal nanocrystals," Nanotechnology, vol. 14, no. 7, pp. R15-R27, 2003.

[5] M. Danilczuk, K. Długopolska, T. Ruman, and D. Pogocki, "Molecular sieves in medicine.," Mini reviews in medicinal chemistry, vol. 8, no. 13, pp. 1407-1417, 2008.

[6] M. E. Davis, "Ordered porous materials for emerging applications," Nature, vol. 417, no. 6891, pp. 813-821, 2002.

[7] C. Laurino and B. Palmieri, "Zeolite: the magic stone ; main nutritional, environmental, experimental and clinical fields of application," Nutrici $\leq n$ Hospitalaria, vol. 32 , no. 2, pp. 573-581, 2015.

[8] J. Jiang, R. Babarao, and Z. Hu, "Molecular simulations for energy, environmental and pharmaceutical applications of nanoporous materials: From zeolites, metal-organic frameworks to protein crystals," Chemical Society Reviews, vol. 40, no. 7, pp. 3599-3612, 2011.

[9] L. A. Delouise, "Applications of nanotechnology in dermatology," Journal of Investigative Dermatology, vol. 132, no. 3, pp. 964-975, 2012.

[10] E. Koohsaryan and M. Anbia, "Nanosized and hierarchical zeolites: A short review," Cuihua Xuebao/Chinese Journal of Catalysis, vol. 37, no. 4, pp. 447-467, 2016.

[11] S. E. Lehman and S. C. Larsen, "Zeolite and mesoporous silica nanomaterials: Greener syntheses, environmental applications and biological toxicity," Environmental Science: Nano, vol. 1, no. 3, pp. 200-213, 2014.

[12] A. Datt, N. Ndiege, and S. C. Larsen, "Development of Porous Nanomaterials for Applications in Drug Delivery and Imaging," in Nanomaterials for Biomedicine, vol. 1119 of ACS Symposium Series, pp. 239-258, American Chemical Society, Washington, DC, 2012.

[13] C. Colella, "A critical reconsideration of biomedical and veterinary applications of natural zeolites," Clay Minerals, vol. 31, no. 2, pp. 295-309, 2011.

[14] K. Pavelić, M. Hadžija, and L. Bedrica, "Natural zeolite clinoptilolite: new adjuvant in anticancer therapy," Journal of Molecular Medicine, vol. 78, no. 12, pp. 708-720, 2001.

[15] C. Sanchez, P. Belleville, M. Popall, and L. Nicole, "Applications of advanced hybrid organic-inorganic nanomaterials: from laboratory to market," Chemical Society Reviews, vol. 40, no. 2 , pp. 696-753, 2011.

[16] The Database of Zeolite Structures, http://www.iza-structure .org/databases/.

[17] S. Calero, "Simulación molecular de la adsorción de hidrocarburos en zeolitas con cationes de intercambio," Anales de Química, vol. 102, no. 1, pp. 21-26, 2006.

[18] L. Zhao, J. G. Yu, X. J. Zhao, B. Cheng, Z. Q. Zhang, and R. Guo, "Research and development of mesoporous nanostructured materials," Rare Metal Materials Engineering, vol. 33, no. 1, p. 10, 2004.

[19] Y. Feng, N. Panwar, D. J. H. Tng, S. C. Tjin, K. Wang, and K.-T. Yong, "The application of mesoporous silica nanoparticle family in cancer theranostics," Coordination Chemistry Reviews, vol. 319, pp. 86-109, 2016.

[20] Y. Wang, Q. Zhao, and N. Han, "Mesoporous silica nanoparticles in drug delivery and biomedical applications," Nanomedicine: Nanotechnology, Biology and Medicine, vol. 11, no. 2, pp. 313-327, 2015.

[21] E. Dündar-Tekkaya and Y. Yürüm, "Mesoporous MCM-41 material for hydrogen storage: A short review," International Journal of Hydrogen Energy, vol. 41, no. 23, pp. 9789-9795, 2016.

[22] M. A. Hernandez, F. Rojas, F. Hernández, and M. A. Salgado, "Nanopore organic-inorganic hybrid materials with properties of cell regeneration: Physicochemical and morphological characterization," in Proceedings of the 21st International Materials Research Congress, IMRC 2012, pp. 20-26, mex, August 2012.

[23] M. Á. Hernández, F. Rojas, R. Portillo, M. A. Salgado, V. Petranovskii, and K. Quiroz, "Textural Properties of Hybrid Biomedical Materials Made from Extracts of Tournefortia hirsutissima L. Imbibed and Deposited on Mesoporous and 
Microporous Materials," Journal of Nanomaterials, vol. 2016, Article ID 1274817, 2016.

[24] M. M. J. Treacy and J. B. Higgins, Collection of simulated XRD Powder patterns for zeolites, Elsevier, Amsterdam, The Netherlands, 4th edition, 2001.

[25] G. S. Armatas, D. E. Petrakis, and P. J. Pomonis, "A method of distinction between microporosity and mesoporosity using BET-Scatchard plots," Microporous and Mesoporous Materials, vol. 83, no. 1-3, pp. 251-261, 2005.

[26] F. Rouquerol, J. Rouquerol, K. S. W. Sing, P. Llewellyn, and G. Maurin, Adsorption by Powders and Porous Solids, Elsevier, Amsterdam, The Netherlands, 2014.

[27] M. J. Remy and G. Poncelet, "A new approach to the determination of the external surface and micropore volume of zeolites from the nitrogen adsorption isotherm at $77 \mathrm{~K}$," Journal of Physical Chemistry, vol. 99, no. 2, pp. 773-779, 1995.

[28] R. A. Roberts, K. S. W. Sing, and V. Tripathi, "Adsorption of nitrogen and neopentane vapor by microporous carbons," Langmuir, vol. 3, no. 3, pp. 331-335, 1987.

[29] J. C. Groen, L. A. A. Peffer, and J. Pérez-Ramírez, "Pore size determination in modified micro- and mesoporous materials. Pitfalls and limitations in gas adsorption data analysis," Microporous and Mesoporous Materials, vol. 60, no. 1-3, pp. 1-17, 2003.

[30] C. K. Modi and P. M. Trivedi, "Synthesis, characterization and catalytic behaviour of entrapped transition metal complexes into the zeolite Y," Advanced Materials Letters, vol. 3, no. 2, pp. 149-153, 2012.

[31] M. Thommes, K. Kaneko, A. V. Neimark et al., "Physisorption of gases, with special reference to the evaluation of surface area and pore size distribution (IUPAC Technical Report)," Pure and Applied Chemistry, vol. 87, no. 9-10, pp. 1051-1069, 2015.

[32] V. Dondur, V. Rakić, L. Damjanović, and A. Auroux, "Comparative study of the active sites in zeolites by different probe molecules," Journal of the Serbian Chemical Society, vol. 70, no. 3, pp. 457-474, 2005. 

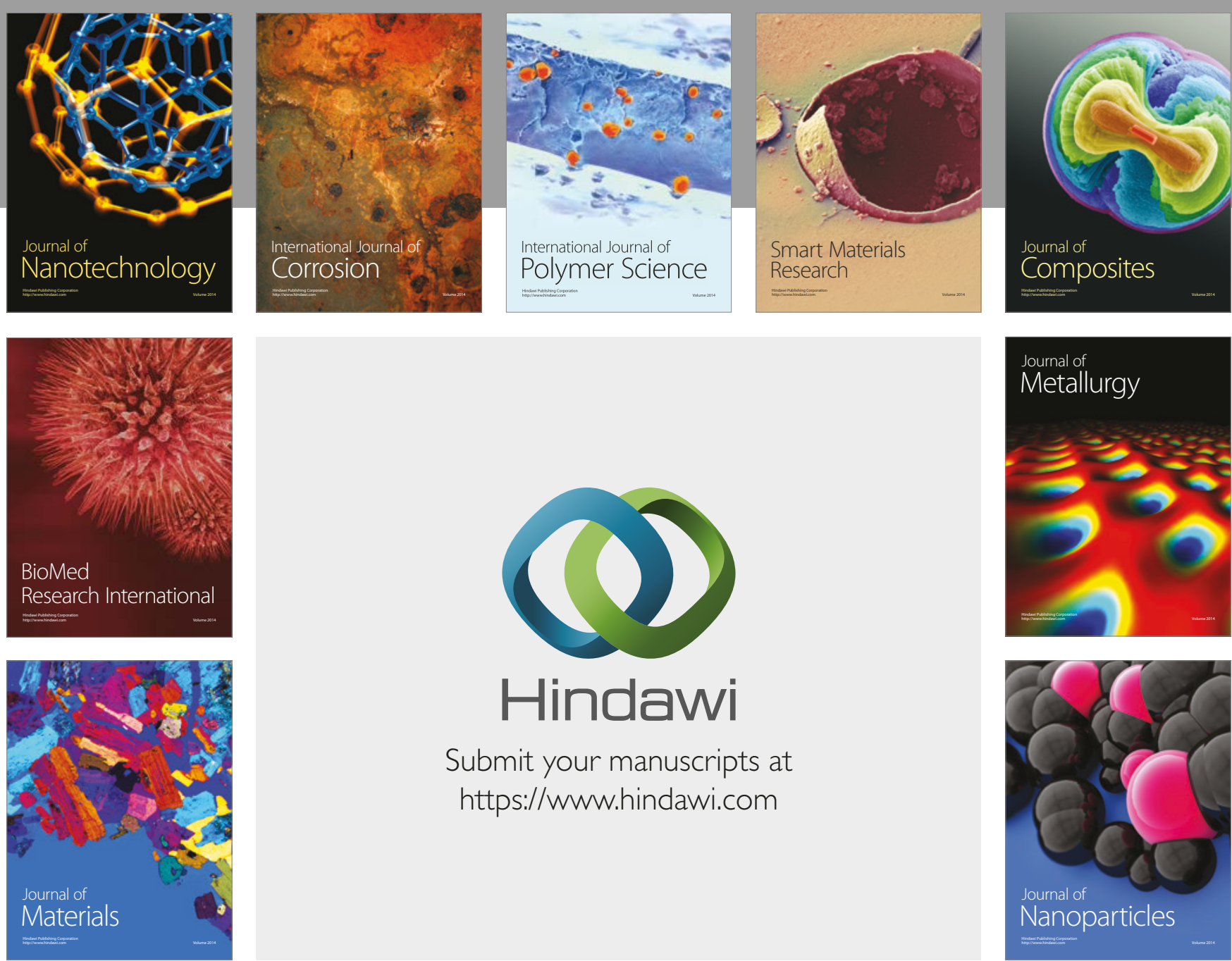

\section{Hindawi}

Submit your manuscripts at

https://www.hindawi.com
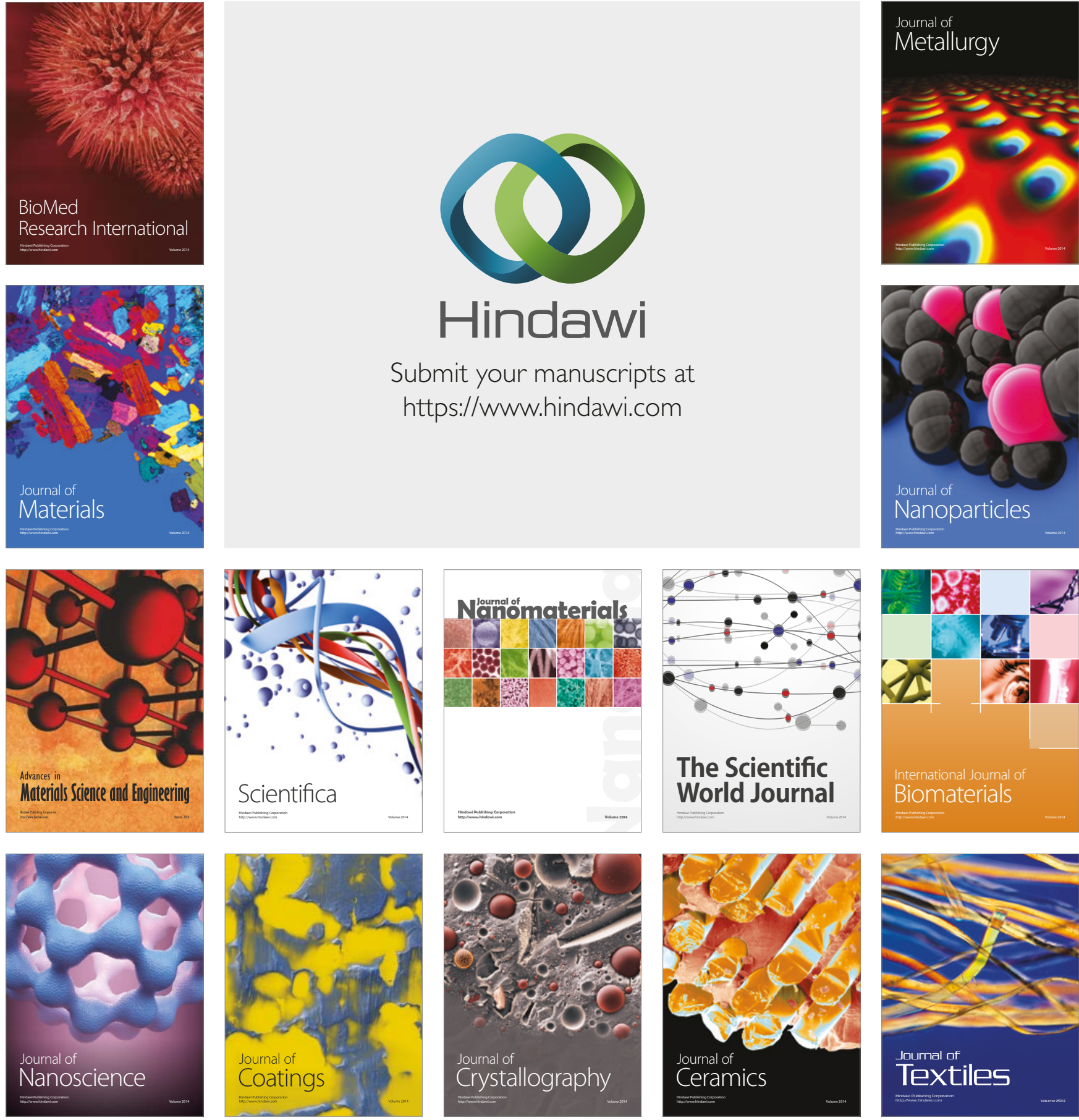

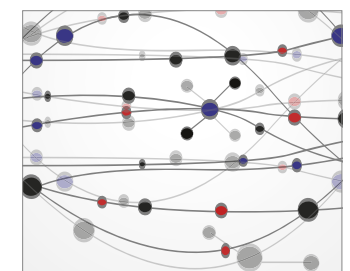

The Scientific World Journal
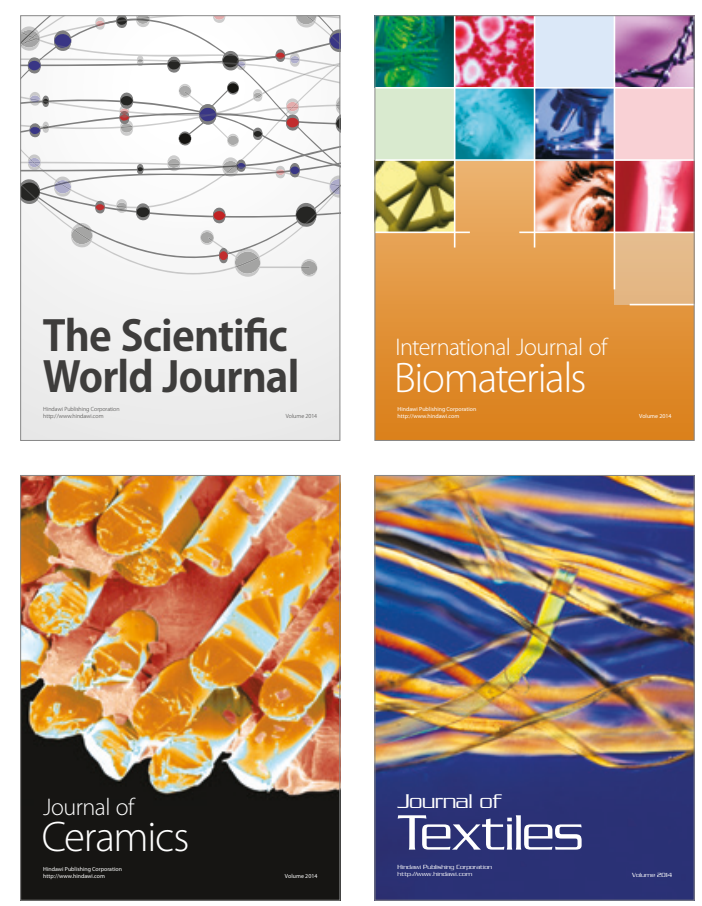